\title{
Uma Proposta de Indicadores para Avaliar a Qualidade de Disciplinas Semipresenciais em Cursos de Graduação
}

\author{
Júlio C. G. Bertolin ${ }^{1}$ \\ Ana Carolina Bertoletti De Marchi ${ }^{1}$
}

\begin{abstract}
Resumo: Este artigo aponta um conjunto de indicadores para a avaliação da qualidade de disciplinas semipresenciais de cursos de graduação presenciais. Inicialmente, é realizada uma revisão da literatura acerca das diferentes concepções de qualidade da educação superior com vistas a estabelecer um entendimento de qualidade para disciplinas semipresenciais. Logo após, são abordados os sistemas de indicadores utilizados em instrumentos de avaliação da educação superior para subsidiar a elaboração dos indicadores para disciplinas semipresenciais. Por fim, considerando-se as especificidades da semipresencialidade, são apontados os aspectos de entrada, de processo e de resultados para avaliar a qualidade de disciplinas semipresenciais, bem como para servir de subsídio para a elaboração de instrumentos de avaliação.
\end{abstract}

Palavras-chave: Educação Superior. Sistema de indicadores. Disciplinas semipresenciais. Avaliação da semipresencialidade.

\begin{abstract}
This article suggests a set of indicators to evaluate the quality of semi-presencial subjects of presence graduation programs. Initially, it conducted a literature review about the different quality conceptions of college education in order to establish an understanding of quality for semi-presencial subjects. Soon after, the indicators systems used in instruments for assessment of college education are boarded to support the development of indicators for semi-presencial subjects. Finally, considering the specificities of the semi-presencial learning, aspects of entry, process and results are pointed out to evaluate the quality of semi-presencial subjects, as well as providing a subsidy for the development of assessment tools.
\end{abstract}

Keywords: College education. Indicators system. Semi-presencial subjects. Assessment of semipresencial learning.

\section{Introdução}

O Sistema de Educação Superior (SES) brasileiro tem apresentado, nos últimos anos, uma significativa expansão na oferta de cursos de graduação na modalidade de Educação a Distância (EaD). Tal modalidade tem se mostrado uma importante alternativa não apenas para ampliar as baixas taxas de atendimento da educação superior brasileira, mas, também, para tornar mais acessível a pós-graduação e possibilitar o aperfeiçoamento profissional com formação continuada.

No bojo desse fenômeno, também se tem observado a emergência de disciplinas semipresenciais que desenvolvem atividades a distância no âmbito de cursos presenciais. De acordo com a portaria 4.059/2004, as disciplinas semipresenciais ocorrem exclusivamente em cursos de graduação presenciais que podem desenvolver até $20 \%$ do total da sua carga horária na modalidade a distância. Dentro do escopo da disciplina, as atividades a distância podem compor até $80 \%$ da sua carga horária. Dessa forma, uma disciplina semipresencial tem como característica marcante o desenvolvimento da modalidade $\mathrm{EaD}$ num contexto de predominância de aulas e atividades presenciais.

\footnotetext{
${ }^{1}$ Curso de Ciência da Computação, UPF, Campus 1 - BR 285 - Passo Fundo (RS) - Brasil

\{julio, carolina@upf.br\}
}

doi: $10.5335 /$ rbca. 2009.004

Revista Brasileira de Computação Aplicada (ISSN 2176-6649), Passo Fundo, v.1, n. 1, p. 30-41, set. 2009 
Assim como num curso EaD, as disciplinas semipresenciais flexibilizam o processo de aprendizagem em relação ao tempo e ao espaço. No caso dos cursos presenciais, tal flexibilização está limitada a uma pequena parcela do tempo total de integralização curricular (no máximo $20 \%$ da carga horária total). Todavia, noutros aspectos a semipresencialidade pode agregar ganhos na formação para os alunos de cursos presenciais, tais como: (i) o desenvolvimento da autonomia e da disciplina, visto que as atividades EaD demandam tais comportamentos e (ii) o desenvolvimento de habilidades no uso das tecnologias de informação e comunicação (TIC), que são ferramentas necessárias para um adequado acompanhamento dos conteúdos a distância. Nessa perspectiva, a oferta de disciplinas semipresenciais num curso de graduação pode ser de grande relevância, visto que possibilitam a complementação da formação integral do aluno pelo aprimoramento do perfil comportamental e das habilidades no uso de ferramentas tecnológicas importantes para o profissional contemporâneo.

Apesar de existirem várias pesquisas sobre a qualidade da modalidade EaD, o desenvolvimento de estudos sobre a qualidade das disciplinas semipresenciais se faz necessário, em primeiro lugar, por se tratar de uma experiência relativamente recente, com raras investigações avaliativas, e, em segundo, pela situação de excepcionalidade das disciplinas semipresenciais no contexto da $\mathrm{EaD}$, visto que as atividades a distância, com emprego de recurso tecnológicos e material digital, são trabalhados de forma concomitante com aulas presenciais.

O presente artigo busca contribuir com o desenvolvimento da semipresencialidade ao apresentar um conjunto de indicadores de entrada, de processo e de resultados para avaliar a qualidade de disciplinas semipresenciais, bem como servir de subsídios para a elaboração de instrumentos de avaliação. Para embasar tal proposta são considerados como referenciais teóricos aspectos conceituais de qualidade em educação superior e modelos de sistemas de indicadores para avaliar sistemas educacionais.

\section{Uma concepção de qualidade para disciplinas semipresenciais}

Atualmente, uma das palavras mais empregadas nos trabalhos e pesquisas no campo da educação superior (ES) é o termo "qualidade". Diversas definições de qualidade começaram a surgir durante a década de 1980. Em 1983, Groot afirmou que a qualidade é determinada pelo grau em que um conjunto prévio de objetivos é satisfeito; em 1985, C. Ball definiu qualidade como ajuste ao propósito e, pouco depois, qualidade foi discutida em termos da noção de valor agregado por T. Barnett, em 1988, e J. C. McClain, D. W. Krueger e T. Taylor, em 1989 [1].

Entretanto, foi na década de 1990 que surgiram as principais propostas de categorizações das diversas maneiras de se pensar a qualidade em ES, com destaque para Barnett em 1992 [2], Harvey e Green em 1993 [3] e Green em 1994 [4]. Lee Harvey e Diana Green publicaram, provavelmente, a mais conhecida das propostas de classificação de qualidade em ES na revista Assessment \& Evaluation in Higher Education. No artigo intitulado "Defining quality" os autores compilaram a ampla diversidade de concepções existentes em cinco grupos distintos: qualidade como fenômeno excepcional, qualidade como perfeição ou coerência, qualidade como ajuste a um propósito, qualidade como relação custo-benefício e qualidade como transformação.

Até recentemente, desde as propostas de taxionomias de qualidade em ES publicadas durante a década de 1990, a literatura especializada não apresentou novidades significativas sobre estudos de classificações e de conceitos sobre o assunto. Entretanto, nos últimos anos tem-se observado a emergência de novos termos para explicar as propriedades da qualidade em ES, tais como empregabilidade, eficiência, diferenciação, relevância, pertinência e equidade. Tal fato se deve, provavelmente, ao desenvolvimento de pesquisas segundo novas perspectivas e ao envolvimento de uma maior diversidade de stakeholders $^{2}$ e organismos internacionais com os assuntos avaliação, medição e garantia da qualidade em educação. De acordo com Bertolin [5], tais termos parecem surgir sempre vinculados às principais ideias sobre as missões da educação superior neste início de século: (i) competitividade e crescimento econômico, (ii) desenvolvimento sociocultural e crescimento

${ }^{2} \mathrm{O}$ termo stakeholder refere-se aos grupos de interesses existentes em relação à educação superior e a sua qualidade, dentre os quais se destacam governos, docentes, alunos, técnico-administrativos e empregadores. "In the context of higher education quality, stakeholders are those groups that have inter alia an interest in the quality of provision and standard of outcomes. These include government, employers, students, academic and administrative staff, institutional managers, prospective students and their parents taxpayers" [6]. 
econômico sustentável; ou, ainda, (iii) a uma visão de educação superior com missão primordial de coesão e equidade social. Desta forma, o autor agrupa os novos termos em três visões distintas de qualidade em educação superior: visão economicista (empregabilidade e eficiência), visão pluralista (diferenciação, relevância, pertinência) e visão de equidade.

Não obstante tais propostas de classificação, o debate acerca do entendimento de qualidade em ES continua em aberto. Ainda no início da década de 1990, Vroeijenstijn [7] dizia que "é uma perda de tempo tentar definir qualidade", baseando-se no argumento de que se trata de um conceito relativo e que diferentes stakeholders em educação superior têm diferentes prioridades, com focos de atenção provavelmente diferenciados. De fato, é vasta na literatura das duas últimas décadas a afirmação de que qualidade em educação e, especificamente, em educação superior não possui um único significado. A conclusão a que estudos acerca de qualidade em ES tendem a chegar é de que existem diversos, diferentes e legítimos entendimentos para o termo. Independentemente do nível de análise, sistema, instituição, curso ou disciplina, o entendimento de qualidade em ES sempre pode variar no tempo e no espaço. Assim, é perfeitamente possível que a qualidade em ES tenha um significado para um grupo e, ao mesmo tempo, tenha outros, bem distintos, para outros grupos.

Segundo Woodhouse [8], do muito que foi escrito envolvendo o significado de qualidade em ES e das muitas definições sugeridas, a ideia que geralmente é mais aceita está ligada à qualidade como "ajuste ao propósito" (fitness for purpouse). Para esta concepção somente existe qualidade na medida em que serviço educacional se ajusta às exigências para cuja satisfação foi concebido e realizado. Trata-se de uma definição funcional da qualidade. Nesse sentido, um serviço "perfeito" é totalmente inútil se não serve para satisfazer à necessidade para a qual foi criado. Para muitos autores, essa visão de qualidade (fitness for purpouse) permite às instituições definirem seus propósitos em suas missões e seus objetivos; assim, a qualidade é demonstrada pelo logro deles, o que também possibilitaria a existência de variabilidade de entendimentos.

Assim, ao se aplicar a ideia de qualidade como ajuste aos propósitos no âmbito específico da semipresencialidade, é possível estabelecer o entendimento de que uma disciplina semipresencial somente possuíra qualidade se, e somente se, conseguir atingir os seus objetivos, quais sejam (i) a efetiva aprendizagem dos alunos, (ii) a flexibilização da aprendizagem no tempo e no espaço, (iii) o desenvolvimento do comportamento de autonomia e disciplina nos alunos, (iv) a aquisição de habilidades no uso das TIC pelos alunos.

\section{Os sistemas de indicadores para avaliação da educação superior}

Nos últimos tempos os sistemas de indicadores têm sido um dos instrumentos mais importantes e utilizados em âmbito mundial para estudar e analisar o desenvolvimento, o desempenho e a qualidade da educação em diferentes níveis, tais como de sistema, de instituição ou de curso. Alguns dos mais importantes organismos internacionais, como, por exemplo, a Unesco e a OCDE, têm desenvolvido, elaborado e aplicado sistemas de indicadores com vistas a avaliar sistemas de educação.

Alguns organismos e pesquisadores compreendem que uma concepção de qualidade pode ser representada por sistemas de indicadores. Em publicação de 1966, Cheng apud [9] definiu qualidade educacional como "as características de um conjunto de elementos na entrada, processo, e saída do sistema educacional que proporcionam serviços que satisfazem completamente estratégias dos envolvidos internos e externos, contemplando suas implícitas e explícitas expectativas". Da mesma forma, para Estrada [10], a avaliação da qualidade em educação se "expressa como um juízo de valor sobre um atributo ou um conjunto de atributos acerca dos insumos [ou entradas], processos, resultados ou produtos educativos, ou das relações entre eles".

O entendimento conceitual do Laboratorio Latinoamericano de Evaluación de la Calidad de la Educación da Unesco [11] também se reporta a indicadores ao afirmar que a qualidade em educação possui "estreita relação com o nível de logro dos objetivos educacionais, no marco dos programas oficiais de estudo, levando em conta as variáveis de insumo [ou entradas] e especialmente processo". O conceito subjacente do órgão determina que

o nível de qualidade da educação consiste basicamente na definição de um conjunto de variáveis que proporcione, em forma sistemática, um quadro confiável e válido acerca do estado dos sistemas de educação e que pode ser utilizado para colaborar na orientação e ações de melhoria [11]. 
De acordo com Garcia [12], os sistemas de indicadores procuram superar a obtenção de uma simples soma de dados ao agrupar indicadores simples ou compostos em função de fatores e aspectos que lhes deem sentido e uma visão significativa do estado dos sistemas de educação.

Dentre os principais sistemas de indicadores da atualidade estão os desenvolvidos pela Unesco e OCDE. $\mathrm{O}$ projeto Strategic Indicators for Higher Education in the Twenty-First Century, coordenado pelo European Centre for Higher Education da Unesco, Bucareste, Romênia, procura estabelecer um sistema de indicadores estratégicos para monitorar o nível de desenvolvimento dos sistemas de educação superior dos países membros da entidade. O projeto está relacionado com os dois documentos que resultaram da Conferência Mundial da Educação Superior ocorrida em Paris em 1998: o "Higher education in the twenty-first century: vision and action" e o "Framework for priority action for change and development of higher education" [13]. A OCDE também tem se ocupado com a avaliação por meio de medição de sistemas de indicadores. Aspectos relacionados à missão da educação superior, acesso e equidade, qualidade da oferta, recursos humanos, recursos financeiros e internacionalização são abordados pela OCDE com vistas ao desenvolvimento da avaliação do sistema global de educação superior [14].

Essas experiências de avaliação com sistemas de indicadores pelos organismos internacionais e as publicações científicas que vinculam avaliação com sistemas de indicadores consideram que a qualidade em educação é um conceito múltiplo que não pode ser avaliado por apenas um indicador e deve envolver todos os elementos fundamentais do sistema ou processo. Assim, pode-se dizer que é possível avaliar a qualidade em educação por meio de juízo de valor sobre um conjunto de atributos, aspectos ou indicadores acerca das entradas, processo e resultados ${ }^{3}$ educativos, ou das relações entre eles.

Geralmente, os indicadores de entradas referem-se aos recursos, tanto financeiros como humanos e tecnológicos, que se destinam à educação. Aspectos relativos aos gastos com educação, investimento com tecnologia de informações e quantidade e formação dos docentes também podem estar incluídos entre os indicadores de entrada e/ou recursos. Os indicadores de processo referem-se ao contexto pedagógico e organizacional, ou seja, dizem respeito às características primárias, relativas à participação direta do processo de educação, e secundárias, relativas ao apoio à organização das características primárias. Aspectos relativos ao número de horas de ensino, número de horas, dedicação dos docentes, acesso e utilização das TIC podem compor a estrutura dos indicadores de processo. Os indicadores de resultados referem-se às características relativas aos propósitos intermediários e últimos da educação; nível de êxito dos alunos em exames, proporção de aprovados e taxas de escolarização e impactos no desenvolvimento econômico e social podem estar entre os indicadores de resultados [10], [15], [16] e [17].

Tabela 1. Estrutura básica do sistema de indicadores para a educação superior

\begin{tabular}{c|l}
\hline Aspectos de entradas & $\begin{array}{c}\text { Gastos com educação, investimento com tecnologia de informações e } \\
\text { quantidade e formação dos docentes. }\end{array}$ \\
\hline Aspectos de processo & $\begin{array}{l}\text { Contexto pedagógico e organizacional ou características primárias, } \\
\text { relativas à participação direta do processo de educação, e secundárias, } \\
\text { relativas ao apoio à organização das características primárias. }\end{array}$ \\
\hline Aspectos de resultados & $\begin{array}{l}\text { Características relativas aos propósitos intermediários e últimos da } \\
\text { educação. }\end{array}$ \\
\hline
\end{tabular}

Fonte: Adaptado de [5].

\footnotetext{
${ }^{3}$ Existe certa variedade de denominações para representar os indicadores relacionados aos propósitos dos sistemas de educação, tais como "produtos", "resultados" ou "saídas" dos sistemas. Neste estudo é adotada, predominantemente, a denominação de "indicadores de resultados" para todos os aspectos relativos aos mais diversos propósitos de um sistema de educação.
} 
Não obstante a existência e a possibilidade de outras formas de organização, os sistemas de indicadores estruturados sistemicamente (Tabela 1) tornaram-se um dos métodos mais empregados para avaliar a qualidade em educação superior. Ainda não existe um consenso geral sobre a quantidade necessária, tampouco sobre os aspectos mais apropriados para comporem um sistema de indicadores, entretanto está claro que a existência de elementos de entradas, de processo e de resultados do objeto de análise (ex: sistema, instituição, curso ou disciplina) é fundamental.

Segundo James [18], nem tudo que é avaliável em educação superior é mensurável, e os indicadores qualitativos são necessários para aspectos importantes do processo educacional. Dessa forma, muitos sistemas de indicadores no campo da educação também incluem indicadores de natureza qualitativa. Um indicador, apesar de ser instrumento de alcance limitado, pode possuir grande relevância e difusão em função de duas características intrínsecas: capacidade de síntese e de orientar a tomada de decisão [19]. Pode-se dizer que os indicadores se diferenciam do conceito de standard principalmente em razão da condição prévia de mensuração deste último, ou seja, diferentemente de um standard, um "indicador" não contém uma mensuração ou medida prévia desejável que sirva como referencial para comparações.

Pela análise da literatura, percebe-se que existe consenso acerca de algumas características necessárias para a definição de indicadores úteis e confiáveis com vistas à avaliação da educação [12], [20] e [17], entre as quais se destacam:

- relevância e significância: devem gerar informações significativas sobre aspectos relevantes;

- imediatez: devem facilitar uma ideia rápida e global da situação do sistema de educação;

- validade e confiabilidade: devem se relacionar com informações reconhecidas como válidas e confiáveis;

- exequibilidade: a obtenção de suas informações deve ser exeqüível operacional e economicamente;

- perdurabilidade: deve possibilitar o estabelecimento de estudos e comparações longitudinais do sistema de educação.

Em trabalho desenvolvido para a Unesco, James [18] procurou sumarizar o que as experiências nacionais e internacionais acumularam acerca dos indicadores de sistemas de educação nos últimos anos:

- indicadores que são abstratos ou baseados em fórmulas complexas não são facilmente interpretados - ou são mal interpretados - pelos vários stakeholders com interesse na educação superior. Simplicidade é uma virtude, e os indicadores devem ser transparentes e facilmente validados;

- não obstante o valor da simplicidade, o indicador que é excessivamente "puro" possui tênues ligações com os objetivos e não detecta diferenças não explícitas ou as mudanças temporais que têm pouco valor, o que pode ocasionar negligências;

- os resultados mais úteis estrategicamente são alcançados quando um acordo sobre a estrutura de coleta de dados e relatório é estabelecido. Particularmente, se a análise comparativa deve ser empreendida, a definição de indicadores deve ser precisa e as variáveis quantitativas devem possuir adequadas propriedades psicométricas;

- para a maioria dos fins relativos às questões políticas, a quantidade de indicadores deve ser mínima, do contrário o levantamento de dados tende a tornar-se um fim em si mesmo. As experiências das atividades de benchmarking no mundo dos negócios é que uma grande quantidade de indicadores numéricos cria problemas de gerenciamento e coleta de dados que dispersam a análise e o uso das conclusões;

- quando existem indicadores "simples" ou "absolutos", esses raramente são neutros. A criação dos indicadores estabelece uma hierarquia de valores, e o ato de medir ou relatar afeta o objetivo da mensuração. Selecionar indicadores liga prioridades a certas metas e funções e, em longo prazo, pode redirecionar recursos já acordados. A tendência normativa dos indicadores é valiosa em muitas circunstâncias, mas eles podem atuar contra a diversidade institucional dentro dos sistemas;

- a categorização dos indicadores é útil na elaboração de projetos exequíveis. A maioria dos indicadores de educação superior assume um modelo de processo e produção representando a educação superior como um sistema de entradas, processos e saídas. Os indicadores de saídas - ou de resultados são geralmente os mais difíceis de se mensurar e requerem considerável interpretações subjetivas; 
- os dados quantitativos "puros" geralmente requerem modificações antes que possam transmitir significado suficiente para guiar políticas e ações. A modificação necessária pode envolver representações como percentuais ou o cálculo de uma tendência temporal;

- uma característica da educação superior é o longo tempo existente entre as ações e os resultados em muitas áreas importantes. Esse longo tempo cria dificuldades particulares para se mensurar quantitativamente se os propósitos estão melhorando continuamente. Portanto, a análise dos indicadores e todas as ações planejadas devem levar em conta o horizonte de tempo para os resultados;

- o sentido de medida de alguns indicadores é questionável, dependendo se foram supostos para medir qualidade ou eficiência. Além disso, a interpretação de certos indicadores de resultados pode auxiliar a análise da qualidade das saídas. Se "despesas por estudante" for tomado como um exemplo, de acordo com uma interpretação, o alto custo unitário pode ser usado como um indicador de processo com alta qualidade educacional. O baixo custo unitário, por outro lado, pode ser interpretado como uma medida de eficiência;

- as medidas dos impactos da qualidade do ensino, pesquisa e valor-agregado da educação superior são particularmente alusivas e sujeitas aos efeitos da reputação ou status. Os atuais indicadores de performance para a qualidade de ensino têm bases conceituais alternativas e a maioria possui um elemento de alta subjetividade;

- uma das questões mais importantes para a maioria dos projetos de indicadores é o que fazer após a coleta de dados. Indicadores não fazem, por si mesmos, especificações de ações a serem tomadas. As ações requerem uma interpretação do significado dos indicadores dentro de uma maior compreensão do contexto. Inevitavelmente, há uma dimensão comparativa dos indicadores projetados, mesmo que não esteja explicitado. Comparações são valiosas - talvez indispensáveis para informar e guiar as políticas e ações. Comparações podem ser feitas em relação ao tempo que passou, em relação aos objetivos, ou com outros sistemas e organizações similares. Quando os indicadores são fortemente dependentes do contexto social, político e econômico, as comparações realizadas com outros sistemas ou organizações devem ser empreendidas de forma cautelosa e ciente das diferenças contextuais;

- uma vez que a informação do indicador está disponível, há uma tendência de que seja usada para finalidades distintas da sua criação. Dentro dos sistemas mais orientados ao mercado, os indicadores no nível institucional fornecem informações comercialmente sensíveis e que são de interesse dos estudantes. Indicadores em nível de sistema podem atrair pouca atenção desta natureza;

- a coleta de bons dados tem alto custo e os recursos adequados precisam estar disponíveis e separados para a coleta, análise e relatório. Genericamente falando, a cooperação das instituições para fornecer dados para indicadores em nível de sistema é vital porque a coleta de determinadas informações somente é possível se realizada em nível institucional.

Certamente, o uso de indicadores para referenciar a qualidade de um sistema de educação não está imune a críticas ou isento de polêmicas. Não raramente, os indicadores são acusados de não propiciar a explicação das causas das situações e de suporem simplificações da realidade que não são úteis para a efetiva melhora das instituições e cursos. Assim, muitas das tentativas de avaliações internacionais baseadas em indicadores e instrumentos prioritariamente quantitativos têm sido objeto de críticas epistemológicas e metodológicas [21]. Entretanto, "se avaliação implica em juízo, este deve resultar de observações concretas baseadas em normas ou valores os mais objetivos possíveis" [22], bem como "faz-se necessário objetivar parâmetros educativos de caráter geral, que permitam comparações [...] e a tomada de decisão dos responsáveis políticos pelos sistemas de educação" [19]. No mínimo, deve-se reconhecer que os sistemas de indicadores permitem estabelecer importantes comparações e observar tendências de caráter interno e de desenvolvimento da qualidade da educação por meio da explicitação de séries temporais. Na opinião de Alejandro Tiana,

entre os mecanismos postos em prática para efetuar um diagnóstico de sistemas de educação, quiçá o mais inovador seja a elaboração e cálculo sistemático de indicadores de educação. [...] Não obstante continuar 
submetidos a polêmicas, não cabe dúvida que têm tido uma grande incidência sobre os modos de conceber e utilizar informações acerca da educação [23].

Para Jaume Sarramona,

a conclusão que podemos chegar da polêmica é que, por um lado, as críticas obrigam a revisão constante dos indicadores e, por outro, se generaliza seu emprego em todos os âmbitos da educação, como conseqüência, de um desejo atualmente implacável, de avaliação e, por conseguinte, por comparação de parâmetros referidos, mais ou menos acertadamente, a pretendida qualidade [19].

Enfim, as dificuldades existentes não justificam a não realização de avaliações e medições do desenvolvimento e da qualidade da educação superior baseadas em sistemas de indicadores. Portanto, em face dos objetivos deste artigo, pressupõe-se que a avaliação da qualidade de disciplinas semipresenciais está diretamente relacionada ao acompanhamento de desempenho de um conjunto de indicadores de entradas, de processos e de resultados.

\section{Indicadores para avaliar a qualidade de disciplinas semipresenciais}

A princípio, os processos de avaliação de qualidade de educação desenvolvidos por diferentes métodos necessitam de uma abordagem teórico-conceitual sobre qualidade. Segundo Vlãsceanu, Grünberg e Pârlea [24], os indicadores podem ser "usados para traduzir aspectos teóricos da qualidade num processo conhecido como operacionalização", por meio do qual se constroem modelos para avaliação e medição com base numa concepção ou conceito de qualidade. Assim, a elaboração de um instrumento para avaliar a qualidade de disciplinas requer, inicialmente, o estabelecimento de uma concepção de qualidade e, logo após, a construção de um modelo de avaliação com indicadores.

Com vistas à identificação de um conjunto de indicadores para a avaliação de disciplinas semipresenciais, este trabalho toma como referência a concepção de qualidade como "ajuste aos propósitos", ou seja, uma disciplina semipresencial somente possui qualidade se, e somente se, conseguir atingir seus objetivos de efetiva aprendizagem dos alunos, de flexibilização da aprendizagem no tempo e no espaço, de desenvolvimento do comportamento de autonomia e disciplina nos alunos e de aquisição de habilidades no uso das TIC pelos alunos.

Entretanto, avaliar somente os resultados para verificar se as metas foram atingidas (ou não) pode se tornar um procedimento incompleto ou insuficiente, visto que as entradas e o processo têm importância fundamental na aprendizagem e explicam muitas das causas dos resultados obtidos (Figura 1).

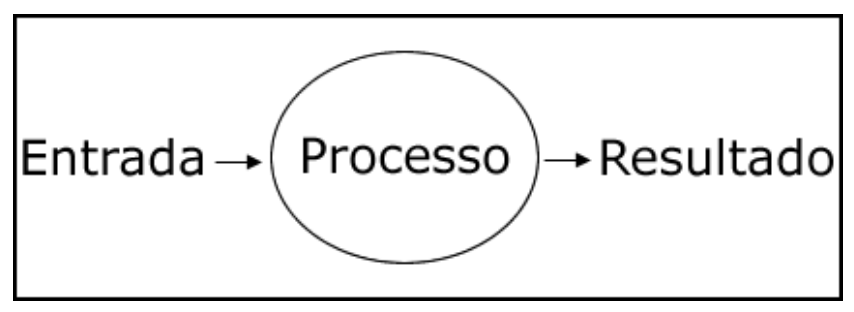

Figura 1. Fluxo dos Indicadores

Nesse sentido, o modelo de indicadores sistêmicos pode ratificar e complementar a ideia de avaliação da qualidade de disciplinas semipresenciais com base na concepção de "ajuste aos propósitos". Ratifica ao estabelecer aspectos de "resultados" para cotejar com os propósitos e complementa ao incluir aspectos da entrada 
e do processo de desenvolvimento das disciplinas que passam a fazer parte da avaliação, indicando, inclusive, evidências de relações de causa e efeito entre os aspectos que fragilizam ou potencializam os resultados.

Dessa forma, o presente trabalho toma $(i)$ o entendimento de qualidade para disciplinas semipresenciais estabelecido nesse trabalho (conforme a concepção de "ajuste aos propósitos") e (ii) o modelo de indicadores sistêmico, estruturado em aspectos de processo e resultados, como bases para elaborar a construção de indicadores para a avaliação de qualidade para disciplinas semipresenciais.

A elaboração de um sistema de indicadores para as disciplinas semipresenciais deve considerar, fundamentalmente, as especificidades de tal modalidade de ensino. Segundo De Marchi et al. [25], a responsabilidade agregada às atividades não presenciais está fundamentada, especialmente, em seis princípios que fazem da semipresencialidade uma opção significativa para a formação de profissionais comprometidos, quais sejam:

- interação e aprendizado colaborativo: permite a construção do conhecimento pelo viés do diálogo e da troca constante de saberes junto aos colegas e professores, que superam a distância física e temporal nas relações interpessoais, tendo em vista o compromisso assumido com o desenvolvimento intelectual, cultural e humano dos sujeitos envolvidos no processo educativo;

- autonomia na aprendizagem: contribui para a formação de um sujeito comprometido com o estudo, responsável pela organização de seu tempo na busca contínua do aprender. O aluno deve assumir sua autonomia, envolvendo-se numa rede de relacionamentos que favoreça o desenvolvimento cognitivo de todo o grupo;

- flexibilização do tempo e do espaço: possibilita a realização das atividades da disciplina em horário e local mais apropriado ao acadêmico, em especial àquele já inserido no mercado de trabalho, reduzindo as horas de deslocamento até a universidade e possibilitando o cumprimento das atividades, de acordo com a necessidade e característica de cada aluno;

- potencialização das ferramentas tecnológicas na educação: considera as tecnologias de informação e comunicação (TIC) a serviço do processo de ensinar e aprender a distância, fomentando a sua apropriação das mesmas em prol da formação humana e profissional, uma vez que o aluno incorpora tal instrumental ao seu cotidiano em busca do cumprimento dos objetivos da disciplina;

- qualidade dos materiais e da metodologia: prevê um processo cuidadoso nas fases de planejamento, desenvolvimento, implantação e avaliação dos materiais a serem adotados nas disciplinas, considerando, ainda, a realidade dos acadêmicos e o atendimento de suas necessidades;

- apoio e suporte: mantém estrutura de apoio técnico e pedagógico ao acadêmico, objetivando a interação permanente com o estudante, o esclarecimento de suas dúvidas e o incentivo para a continuidade dos estudos, de forma a fortalecer o engajamento do aluno com o curso.

Dessa forma, como indicadores de entrada para a avaliação de uma disciplina semipresencial podem ser considerados:

- a qualidade da infraestrutura, onde se destacam: (i) o ambiente virtual de aprendizagem, que ocupa papel fundamental nos momentos a distância como espaço social de interações e (ii) os demais recursos de bidirecionalidade para comunicação e interação professor-aluno-tutor, como a videoconferência;

- o nível da titulação e da formação do professor e tutores para atuarem em disciplinas semipresenciais;

- o perfil sociocultural dos alunos que podem potencializar ou dificultar o acompanhamento da disciplina semipresencial no que se refere à habilidade no uso das TIC;

- a qualidade do planejamento da disciplina com a preparação prévia de seu material didático e das demais mídias a serem empregadas.

Em relação aos aspectos de processo podem ser considerados como indicadores os seguintes parâmetros: 
- a eficácia da dinâmica de interação imprimida entre professor-tutor-aluno, que permite identificar o nível de colaboração entre os sujeitos envolvidos na disciplina;

- a efetividade da tutoria e do suporte aos alunos, no que se refere ao acompanhamento dos alunos quanto às tarefas solicitadas e o contato sistemático;

- a efetividade na articulação entre momentos presenciais e a distância, onde se destaca, principalmente, a adequação do percentual de aulas à distância em relação aos conteúdos previstos;

- a qualidade da prática didático-pedagógica do professor, que atende aos objetivos de aprendizagem da disciplina e possibilita a compreensão do conteúdo;

- a efetiva revisão e readequação do planejamento durante o desenvolvimento da disciplina, adaptando-o no decorrer da disciplina a partir do feedback obtido junto aos alunos, privilegiando a personalização e a contextualização;

- a efetiva flexibilização da aprendizagem no tempo e no espaço pelos alunos, levando em consideração que o aluno não precisa estar fisicamente presente e que as atividades podem ser realizadas ao longo de períodos mais extensos.

Por fim, como aspectos de resultados a serem considerados como objetivos alcançados, este trabalho propõe os seguintes indicadores:

- a efetiva aprendizagem dos alunos, percebendo se o aproveitamento do conteúdo nos momentos a distância foi equivalente às aulas presenciais;

- a efetiva aquisição de habilidades no uso das TIC pelos alunos, procurando identificar se a experiência da semipresencialidade foi importante para a sua aproximação com as ferramentas computacionais;

- o efetivo desenvolvimento do comportamento de autonomia e disciplina nos alunos, onde se destaca: (i) a iniciativa do aluno em suprir dificuldades quanto ao conteúdo e à utilização do ambiente virtual de aprendizagem e (ii) a organização do tempo adequadamente para cumprir as atividades a distância.

Assim, após a observância e embasamento em conceito de qualidade como "ajuste aos propósitos" e no modelo de indicadores sistêmicos, utilizados por organismos internacionais, chegou-se ao sistema de indicadores representado na Tabela 2 , com vistas a avaliar a qualidade de disciplinas semipresenciais.

Tabela 2. Indicadores para disciplinas semipresenciais

\begin{tabular}{l|l}
\hline \multirow{4}{*}{ Aspectos de entradas } & $\begin{array}{l}\text { Qualidade da infraestrutura: ambiente virtual de aprendizagem, } \\
\text { videoconferência etc. }\end{array}$ \\
\cline { 2 - 2 } & Nível da titulação e da formação do professor e tutores \\
\cline { 2 - 2 } & $\begin{array}{l}\text { Perfil sociocultural dos alunos: acesso as TIC, renda familiar, formação } \\
\text { dos pais etc. }\end{array}$ \\
\cline { 2 - 2 } Qualidade do planejamento da disciplina: material didático, mídias etc. \\
\hline \multirow{4}{*}{ Aspectos de processo } & Eficácia da dinâmica de interação imprimida entre professor-tutor-aluno \\
\cline { 2 - 2 } & Efetividade da tutoria e suporte aos alunos \\
\cline { 2 - 2 } & $\begin{array}{l}\text { Efetividade na articulação entre momentos presenciais e à distância: } \\
\text { conteúdos e carga-horária }\end{array}$ \\
\cline { 2 - 2 } Qualidade da prática didático-pedagógica do professor \\
\cline { 2 - 2 } & $\begin{array}{l}\text { Efetiva revisão e readequação do planejamento durante o } \\
\text { desenvolvimento da disciplina }\end{array}$ \\
\cline { 2 - 2 } & $\begin{array}{l}\text { Efetiva flexibilização da aprendizagem no tempo e no espaço pelos } \\
\text { alunos }\end{array}$ \\
\hline & Efetiva aprendizagem dos alunos \\
\cline { 2 - 2 } & Efetiva aquisição de habilidades no uso das TIC pelos alunos \\
\cline { 2 - 2 } & $\begin{array}{l}\text { Efetivo desenvolvimento do comportamento de autonomia e disciplina } \\
\text { pelos alunos }\end{array}$ \\
\hline
\end{tabular}


A proposta é que os indicadores acima apontados sejam utilizados como subsídio para a elaboração de instrumentos de avaliação de disciplinas semipresenciais. A avaliação de uma disciplina semipresencial tem o objetivo de analisar resultados com vistas ao desenvolvimento e à melhoria na qualidade em suas diferentes dimensões. A operacionalização de sistematizações e análises possibilita a identificação de fragilidades e potencialidades de forma a emitir juízo de valor acerca da qualidade da disciplina semipresencial, objetivo último de qualquer processo avaliativo.

\section{Conclusão}

O sistema de indicadores elaborado neste trabalho, muito provavelmente, é a primeira proposta para a avaliação de forma global do desenvolvimento e da qualidade de disciplinas semipresenciais no contexto da educação superior brasileira. Assim como as demais modalidades educacionais, a semipresencialidade necessita adotar sistemas de avaliação com vistas à melhoria da qualidade. Entretanto, não deve importar sistemas prontos de outras modalidades, mas, sim, adaptar e ajustar modelos reconhecidos a sua realidade e especificidade.

Nesse sentido, o presente trabalho, com base num conceito de qualidade para disciplinas semipresenciais e na concepção de "ajuste aos propósitos" e nos modelos de sistema de indicadores sistêmicos estruturado em aspectos de entrada, de processo e de resultados, desenvolveu uma proposta de indicadores para avaliar a qualidade de disciplinas semipresenciais.

Tais indicadores não se limitam a verificar se os objetivos e as metas foram atingidas. Ao abordarem as questões das entradas e do processo, que têm importância fundamental na aprendizagem, podem explicar muitas das causas dos resultados obtidos numa disciplina semipresencial e, por conseguinte, possibilitar a emissão de juízo de valor sobre a qualidade dessas disciplinas.

\section{Referências}

[1] WATTY, K. Quality in accounting education: what say the academics? Quality Assurance in Education, Melbourne, v. 13, n. 2, p. 120-131, 2005.

[2] BARNETT, R. Improving Higher Education - total quality care. Bristol, USA: SRHE and Open University Press, 1992.

[3] HARVEY, L.; GREEN, D. Defining Quality. Assessment \& Evaluation in Higher Education, v. 18, Issue 1, p. 9-26, Apr. 1993.

[4] GREEN, D. What is quality in higher education? Bristol: SRHE and Open University Press, 1994.

[5] BERTOLIN, J. C. G. Avaliação da qualidade do sistema de educação superior brasileiro em tempos de mercantilização - Período 1994-2003. 2007. Tese (Doutorado em Educação) - Universidade Federal do Rio Grande do Sul, Porto Alegre, 2007.

[6] HARVEY, L. Analytic Quality Glossary. Quality Research International: november 2004 - July 2005. Disponível em: <http://www.qualityresearchinternational.com/glossary/>. Acesso em: 3 maio 2006.

[7] VROEIJENSTIJN, T. I. External Quality Assessment: servant of two masters? In: CONFERENCE ON QUALITY ASSURANCE IN HIGHER EDUCATION, 1991, Hong Kong. Hong Kong: HKCAA, 1991.

[8] ORGANISATION ECONOMIC CO-OPERATION AND DEVELOPMENT (OECD). Quality and Internationalisation in Higher Education. Programme on Institutional Management in Higher EducationIMHE. Paris: 1999. 
[9] SAHNEY, S.; BANWET, D. K.; KARUNES S. Conceptualizing total quality management in higher education. The TQM Magazine, v. 16, n. 2, p. 145-159, 2004.

[10] ESTRADA, L. R. G. Hacia un modelo de evaluación de la calidad de instituciones de educación superior. Revista Iberoamericana de Educación - Número 21, Universidad siglo XXI, OEI Ediciones, Dez. 1999.

[11] UNITED NATIONS EDUCATIONAL, SCIENTIFIC AND CULTURAL ORGANIZATION (UNESCO). Marco conceptual. Documentos - Laboratorio Latinoamericano de Evaluación de la calidad de la educación. Santiago, Chile: Lecce, Orealc/Unesco, 1997.

[12] GARCÍA, M. G. Evaluación y Calidad de los Sistemas Educativos. In: RAMÍREZ, Teresa G. (Org.). Evaluación y gestión de la calidad educativa. Málaga: Ediciones Aljibe, 2000.

[13] UNITED NATIONS EDUCATIONAL, SCIENTIFIC AND CULTURAL ORGANIZATION (UNESCO).System-Level and strategic indicators for monitoring higher education in the twenty-first century. Studies on Higher Education. Bucharest: Cepes, 2003.

[14] CENTRO DE INVESTIGAÇÃO DE POLÍTICAS DO ENSINO SUPERIOR (CIPES). Outline of the Background Report for Portugal's Tertiary sector - OECD. Matosinhos: Cipes, 2006.

[15] EUROPEAN COMMISSION. European Report on Quality of School Education. Sixteen quality indicators. Luxembourg: European Communities, 2001.

[16] ORGANISATION ECONOMIC CO-OPERATION AND DEVELOPMENT (OECD). Education at a glance: OECD indicators 2002. Paris, 2002.

[17] NAVARRA. Sistema de indicadores de la educación de Navarra 2003. Navarra: Gobierno de Navarra, 2004.

[18] JAMES, R. Suggestions Relative to the Selection of Strategic System-Level Indicators to Review the Development of Higher Education. In: UNESCO. System-Level and Strategic Indicators for Monitoring Higher Education in the Twenty-First Century. Studies on Higher Education. Bucharest: Unesco-Cepes, 2003.

[19] SARRAMONA, J. Los indicadores de la calidad de la educación. Trabalho apresentado no IX Congresso Interuniversitario de Teoria de la Educación, San Sebastián, 2003. Disponível em: $<$ http://www.cedus.cl/?q=node/521>. Acesso em: 14 jul. 2009.

[20] YONEZAWA, A.; KAISER. What Was Achieved, under What Conditions, and for What Purposes? In: UNESCO. System-Level and Strategic Indicators for Monitoring Higher Education in the TwentyFirst Century. Studies on Higher Education. Bucharest: Unesco-Cepes, 2003.

[21] BOTTANI, N. Ilusão ou ingenuidade? Indicadores de ensino e políticas educacionais, Educação \& Sociedade, Campinas, v. 19, n. 65, dez. 1998.

[22] OEI. Evaluación de la Calidad de la Educación. Revista Iberoamericana de Educación, Buenos Aires, n. 10, p. 215-230, abr. 1996.

[23] TIANA, A. La evaluación de los sistemas educativos. Revista Iberoamericana de Educación, n. 10, p. 37-91, 1996.

[24] VLÃSCEANU, L.; GRÜNBERG, L.; PÂRLEA, D. Quality Assurance and Accreditation: a glossary of basic terms and definitions. Bucharest: Unesco-Cepes Papers in Higher Education, 2004. 
[25] DE MARCHI, A. C. B.; ARAÚJO, D. D. D; STREIT, I. R. Disciplinas semipresenciais em cursos de graduação: relato de experiência da UPF. In: SIMPÓSIO BRASILEIRO DE INFORMÁTICA NA EDUCAÇÃO, 2008, Fortaleza, Brasil, Anais... 2008. 